\title{
Impact of hormone receptor status on patterns of recurrence and clinical outcomes among patients with human epidermal growth factor-2-positive breast cancer in the National Comprehensive Cancer Network: a prospective cohort study
}

Ines Vaz-Luis ${ }^{1,2^{*}}$, Rebecca A Ottesen ${ }^{3}$, Melissa E Hughes', P Kelly Marcom4, Beverly Moy ${ }^{5}$, Hope S Rugo ${ }^{6}$, Richard L Theriault' ${ }^{7}$, John Wilson ${ }^{8}$, Joyce C Niland ${ }^{3}$, Jane C Weeks ${ }^{1}$ and Nancy U Lin ${ }^{1}$

\begin{abstract}
Introduction: In gene expression experiments, hormone receptor (HR)-positive/human epidermal growth factor-2 (HER2)-positive tumors generally cluster within the luminal B subset; whereas HR-negative/HER2-positive tumors reside in the HER2-enriched subset. We investigated whether the clinical behavior of HER2-positive tumors differs by HR status.
\end{abstract}

Methods: We evaluated 3,394 patients who presented to National Comprehensive Cancer Network (NCCN) centers with stage I to III HER2-positive breast cancer between 2000 and 2007. Tumors were grouped as HR-positive/HER2positive (HR+/HER2+) or HR-negative/HER2-positive (HR-/HER2+). Chi-square, logistic regression and Cox hazard proportional regression were used to compare groups.

Results: Median follow-up was four years. Patients with HR-/HER2+ tumors ( $\mathrm{n}=1,379,41 \%$ of total) were more likely than those with HR+/HER-2+ disease ( $n=2,015,59 \%$ of total) to present with high histologic grade and higher stages $(P<0.001)$. Recurrences were recorded for 458 patients. HR-/HER2+ patients were less likely to experience first recurrence in bone (univariate Odds Ratio (OR) =0.53, 95\% Confidence Interval (Cl): 0.34 to 0.82 , $P=0.005$ ) and more likely to recur in brain (univariate $\mathrm{OR}=1.75,95 \% \mathrm{Cl}: 1.05$ to $2.93, P=0.033$ ). A lower risk of recurrence in bone persisted after adjusting for age, stage and adjuvant trastuzumab therapy $(\mathrm{OR}=0.53,95 \% \mathrm{Cl}$ : 0.34 to $0.83, P=0.005$ ) and when first and subsequent sites of recurrence were both considered (multivariable $\mathrm{OR}=0.55,95 \% \mathrm{Cl}: 0.37$ to $0.80, P=0.002)$.

As compared with patients with HR+/HER2+ disease, those with HR-/HER2+ disease had significantly increased hazard of early, but not late, death (hazard ratio of death zero to two years after diagnosis $=1.92,95 \% \mathrm{Cl}$ : 1.28 to 2.86, $P=0.002$, hazard ratio of death two to five years after diagnosis $=1.55,95 \% \mathrm{Cl}$ : 1.19 to $2.00, P=0.001$; hazard ratio of death more than five years after diagnosis $=0.81,95 \% \mathrm{Cl}: 0.55$ to $1.19, P=0.285$, adjusting for age, race/ ethnicity, stage at diagnosis, grade and year of diagnosis).

Conclusions: Presenting features, patterns of recurrence and survival of HER2-positive breast cancer differed by HR status. These differences should be further explored and integrated in the design of clinical trials.

\footnotetext{
* Correspondence: inesV_Luis@dfci.harvard.edu

${ }^{1}$ Department of Medical Oncology, Dana-Farber Cancer Institute, Boston, MA, USA

Full list of author information is available at the end of the article
} 


\section{Introduction}

Breast cancer is a heterogeneous disease, with substantial genotypic and phenotypic diversity [1]. In gene expression experiments, hormone receptor (HR) segregates tumors before human epidermal growth factor 2 (HER2), suggesting that HR status is the most important discriminator of breast cancers. HR-positive is used to categorize breast tumors in two major groups [1-3]: luminal A and luminal $B$ and HR-negative cancers include normal-like, HER2 enriched, basal and claudin-low subtypes [1,4-6]. Most of the clinically HR-positive/HER2-positive $(\mathrm{HR}+/ \mathrm{HER} 2+)$ cancers tend to fall in the luminal B subtype, and most of HR-negative/HER2-positive (HR-/HER2+) in the HER2 enriched subtype [7].

In clinical practice, patients with HR+/HER2+ tumors routinely receive endocrine therapy. In some cases, the threshold to consider chemotherapy and trastuzumab is slightly higher than in patients with HR-/HER2+ tumors. However, despite their molecular differences, HER2-positive tumors are often treated as a single entity, and trials for HER2-positive disease typically include patients irrespective of HR status.

Increasingly, some differences in clinical outcomes, timing and patterns of dissemination within HER2-positive disease according to HR have been reported [8-16]. However, adjuvant trials have frequently reported only the sites of initial, but not subsequent, recurrence. Because of selection bias, studies of patients with metastatic disease are not ideal for examining sites and timing of recurrence associated with HR status in HER-2-positive disease overall.

Since 1997, the National Comprehensive Cancer Network (NCCN) Breast Cancer Outcomes Database has collected data on women with newly diagnosed breast cancer presenting to many of its member institutions across the United States [17]. The large size of the cohort allows for investigation of the impact of HR within HER2-positive breast tumors, with potentially less bias than relying on clinical trial data alone. We aimed to describe clinicopathological features, patterns of recurrence and clinical outcomes of HER2-positive breast cancer according to HR status.

\section{Methods}

\section{Data source}

Data are collected prospectively within the NCCN Database mainly through review of medical records and institutional tumor registries. Vital status and cause of death are determined from medical records and confirmed using the Social Security Death Index and the National Death Index (NDI). Data are subjected to rigorous quality assurance [18]. Institutional review boards from each center approved the study. At centers where a signed informed consent was required, only patients who provided consent were included; elsewhere, the institutional review boards grant a waiver of signed informed consent.

\section{Patient selection}

Patients were included in the analytic group if they presented with newly diagnosed, stage I to III, unilateral, HER2-positive invasive breast cancer between January 2000 and December 2007, at 1 of 13 NCCN institutions: Arthur G. James Cancer Hospital at Ohio State University (Columbus, OH), City of Hope Comprehensive Cancer Center (Duarte, CA), Dana-Farber Cancer Institute (Boston, MA), Duke University Medical Center (Durham, NC), Fox Chase Cancer Center (Philadelphia, PA), H. Lee Moffitt Cancer Center (Tampa, FL), Massachusetts General Hospital (Boston, MA), Robert H. Lurie Comprehensive Cancer Center of Northwestern University (Chicago, IL), Roswell Park Cancer Institute (Buffalo, NY), Seattle Cancer Care Alliance (Seattle, WA), Siteman Cancer Center (St. Louis, MO), The University of Texas M.D. Anderson Cancer Center (Houston, TX), and University of Michigan Comprehensive Cancer Center (Ann Arbor, MI). Of 3,395 eligible women, one had unknown HR status and was excluded, leaving an analysis sample size of 3,394 patients.

\section{Definition of HER2 subgroups}

Tumors were grouped as HR-positive (estrogen receptor (ER) and/or progesterone receptor (PR) positive)/HER2positive and HR-negative (ER and PR negative)/HER2positive, using pathologic information of the primary tumor, as specified below.

\section{Covariates of interest \\ Tumor characteristics}

The database contains information on tumor size, nodal status, grade, lymphovascular invasion (LVI), extensive intraductal component (EIC), ER and PR status and HER2 status, as abstracted from pathology reports. Stage is assigned according to the version of the American Joint Committee on Cancer (AJCC) Staging Manual applicable at the time of diagnosis. Tumor grade was categorized as high (according to histologic grade, or, if not available, by nuclear grade) or low-intermediate. For HER2 classification, we used the fluorescence in situ hybridization (FISH) result, if available. If only immunohistochemistry (IHC) was available, $3+$, "high positive" or "positive NOS" were considered HER2-positive; while $2+, 1+, 0$ or "negative" were considered HER2-negative; $6 \%(n=199)$ of patients were "positive NOS".

\section{Patient characteristics}

We used the following variables collected by chart review: age at diagnosis, height and weight, method of detection, sites of breast cancer recurrence, treatment types and vital status. Body mass index (BMI) was calculated as weight $(\mathrm{kg}) /$ height $(\mathrm{m})^{2}[1]$ and grouped according 
to categories defined by the National Heart, Lung and Blood Institute as follows: $<18.5 \mathrm{~kg} / \mathrm{m} 2$ underweight; 18.5 to 24.9 normal; 25.0 to 29.9 overweight, and $>30.0$ obese.

Data on race/ethnicity, menopausal status and comorbidity score [19] came from patient surveys conducted at initial presentation to the NCCN center. Patients were considered postmenopausal if they were amenorrheic for more than six months prior to breast cancer diagnosis, were taking hormone replacement therapy or were at least 50 years of age without a documented menopausal status in their medical record or baseline patient survey.

\section{Statistical analyses}

\section{Study cohort characterization}

The clinicopathological features at the time of diagnosis were tabulated by HR status and proportions were compared between groups using chi-square tests. This was performed for the overall cohort, and separately among the subgroup of patients with documented recurrence. Treatment variables also were tabulated at the time of diagnosis and at the time of recurrence by HR status.

\section{Sites of recurrence analysis}

Sites of recurrence were tabulated by HR status in the overall cohort, the subgroup of patients with early recurrence (defined as those diagnosed within five years of initial diagnosis) and the subgroup of patients with late recurrence (those diagnosed more than five years from initial diagnosis). In the overall cohort, univariate followed by multivariable logistic regression estimated the risk of sites of recurrence (first and first plus subsequent sites of recurrence). In the multivariable analysis, the estimated risk of recurrence was adjusted by age at diagnosis $(<50, \geq 50$ years), stage at diagnosis (I, II, III), and adjuvant trastuzumab (yes/no).

\section{Agreement between primary and metastatic samples analysis}

Among patients with data from paired primary and metastatic samples, agreement (yes or no) between ER, PR and HER2 status was tabulated and inter-rater agreement between ER, PR and HER2 in primary and recurrent samples was calculated (simple kappa (K) coefficients and asymptotic standard error (ASE) were used).

\section{Survival outcomes analysis}

Follow-up for overall survival (OS) and breast cancer specific survival (BCSS) were defined as time in years from diagnosis to date of death or last known vital status. BCSS was determined by identifying cause of death due to breast cancer based on the International Statistical Classification of Disease codes. Cox proportional hazards regression was used to calculate OS while adjusting for covariates. Hazard ratios and their associated 95\% confidence interval (95\% CI) of any death, and breast cancerspecific death, are presented by HR status (using HR positive as the reference group) and also grouped by HR and adjuvant trastuzumab use. In the latter analysis, the following groups were assembled: patients with HR-positive tumors who received adjuvant trastuzumab, patients with HR-negative tumors who received adjuvant trastuzumab, patients with HR-positive tumors who did not receive adjuvant trastuzumab, and patients with HRnegative tumors who did not receive trastuzumab; the first group was used as the reference group. Cox models were adjusted for age at diagnosis $(<50, \geq 50$ years $)$, race (Caucasian, African American, Other, Unknown), stage at diagnosis (I, II, III), grade (Low/Intermediate, High), and year of diagnosis (2000 to 2007). The risk of death since diagnosis by HR was found to be non-proportional and, therefore, HR was modeled as a time dependent covariate. The cut-points of zero to two, two to five and more than five years were selected $a$ priori because it is well known that, after diagnosis, the peak hazard of recurrence in breast cancer occurs within the first two years, decreases consistently in the interval of two to five years, and decreases even more slowly beyond five years [20]. All $P$-values presented are two-sided; a $P$-value less than 0.05 was considered significant. All statistical analyses were performed using SAS 9.2 (SAS Institute Inc., Cary, NC, USA).

\section{Results}

\section{Description of the study cohort}

A total of 3,394 patients were included in this analysis. Subgroup distribution was: HR+/HER2+ 59\% ( $\mathrm{n}=2,015)$ and HR-/HER $2+41 \%(\mathrm{n}=1,379)$. Median follow-up time was four years (range: 0 to 11 years). The mean age at diagnosis was 52 years. The majority $(79 \%)$ of patients were Caucasian.

\section{Clinicopathological characteristics and patterns of care} Compared to patients with HR+/HER2+ tumors, patients with HR-/HER 2 + tumors were more likely to present with higher $\mathrm{T}$ stage (T3 to T4, $17 \%$ vs. $10 \%, P<0.001$ ), nodal involvement (52\% vs. 45\%, $P<0.001$ ), higher AJCC stage (Stage III, $28 \%$ vs. $18 \%, P<0.001$ ) and higher histologic grade $(81 \%$ vs. $60 \%, P<0.001)$. Approximately onethird of women in both groups presented on the basis of a screening mammogram. Only small absolute differences were observed in the distribution of $\mathrm{HR}+/ \mathrm{HER} 2+$ vs. HR-/HER $2+$ tumors by race or menopausal status (Table 1)

Most (79\%) patients received neoadjuvant or adjuvant chemotherapy. Overall, 44\% of patients received neoadjuvant or adjuvant trastuzumab. As expected, receipt of adjuvant or neoadjuvant trastuzumab increased over time ( $8 \%$ of patients diagnosed in $2000,66 \%$ of patients diagnosed in 2005, and 77\% of patients diagnosed in 2007, data not shown) (Additional file 1, Table S1). 
Table 1 Patient demographics and clinicopathological characteristics for Stage I, II, III patients with HER2-positive breast cancer

\begin{tabular}{|c|c|c|c|c|}
\hline \multicolumn{5}{|l|}{ At time of diagnosis of index cancer } \\
\hline $\begin{array}{l}\text { Variable } \\
\mathrm{N}(\%)\end{array}$ & $\begin{array}{l}\text { Total } \\
(N=3394)\end{array}$ & $\begin{array}{l}\text { HR-positive } \\
(n=2015)\end{array}$ & $\begin{array}{l}\text { HR-negative } \\
(n=1379)\end{array}$ & $P$-value \\
\hline Age, mean (se), y & $52.48(0.21)$ & $52.41(0.29)$ & $52.59(0.32)$ & \\
\hline Age category, $\mathrm{N},(\%)$ & & & & $<.001$ \\
\hline 0 to $<50$ & $1,514(45)$ & $931(46)$ & $583(42)$ & \\
\hline 50 to $<70$ & $1,547(46)$ & $865(43)$ & $682(49)$ & \\
\hline $70+$ & $333(10)$ & $219(11)$ & $114(8)$ & \\
\hline Race/Ethnicity, N, (\%) & & & & 0.030 \\
\hline African-American & $259(8)$ & $135(7)$ & $124(9)$ & \\
\hline Caucasian & 2,693 (79) & $1,627(81)$ & $1,066(77)$ & \\
\hline Hispanic & $262(8)$ & $155(8)$ & $107(8)$ & \\
\hline Asian Pacific Island & $126(4)$ & $64(3)$ & $62(5)$ & \\
\hline American Indian & $10(<1)$ & $4(<1)$ & $6(<1)$ & \\
\hline Other & $16(<1)$ & $10(1)$ & $6(<1)$ & \\
\hline Unknown & $28(1)$ & $20(1)$ & $8(1)$ & \\
\hline Menopausal Status, N, (\%) & & & & 0.001 \\
\hline Premenopausal & $1,569(46)$ & $978(49)$ & $591(43)$ & \\
\hline Postmenopausal & $1,825(54)$ & $1,037(51)$ & $788(57)$ & \\
\hline Body Mass Index kg/m2, N, (\%) & & & & 0.512 \\
\hline$<18.5$ kg/m2 (Underweight) & $52(2)$ & $34(2)$ & $18(1)$ & \\
\hline 18.5 to $<25 \mathrm{~kg} / \mathrm{m} 2$ (Normal) & $1,263(37)$ & $750(37)$ & $513(37)$ & \\
\hline 25 to $<30 \mathrm{~kg} / \mathrm{m} 2$ (Obese) & $913(27)$ & $554(27)$ & $359(26)$ & \\
\hline$>30$ kg/m2 (Severely Obese) & $884(26)$ & $506(25)$ & $378(27)$ & \\
\hline Missing/unknown & $282(8)$ & $171(8)$ & $111(8)$ & \\
\hline Co-morbidity score, N, (\%) & & & & 0.958 \\
\hline 0 & $2,713(80)$ & $1,609(80)$ & $1,104(80)$ & \\
\hline 1 & $452(13)$ & $271(13)$ & $181(13)$ & \\
\hline $2+$ & $229(7)$ & $135(7)$ & $94(7)$ & \\
\hline Method of detection, N, (\%) & & & & $<.001$ \\
\hline Abnormal screening mammogram & $1,209(36)$ & $755(37)$ & $454(33)$ & \\
\hline Symptom & $2,012(59)$ & $1,175(58)$ & $837(61)$ & \\
\hline Other & $147(4)$ & $67(3)$ & $80(6)$ & \\
\hline Unknown & $26(1)$ & $18(1)$ & $8(1)$ & \\
\hline T stage, category, $\mathrm{N},(\%)$ & & & & $<.001$ \\
\hline$T 1$ & $1,753(52)$ & $1,103(55)$ & $650(47)$ & \\
\hline$T 2$ & $1,150(34)$ & $691(34)$ & $459(33)$ & \\
\hline T3 & $244(7)$ & $129(6)$ & $115(8)$ & \\
\hline T4 & $197(6)$ & $73(4)$ & $124(9)$ & \\
\hline Unknown & $50(1)$ & $19(1)$ & $31(2)$ & \\
\hline Nodal status, N, (\%) & & & & $<.001$ \\
\hline Positive & $1,623(48)$ & $907(45)$ & $716(52)$ & \\
\hline Negative & 1,757 (52) & $1,101(55)$ & $656(48)$ & \\
\hline Unknown & $14(<1)$ & $7(<1)$ & $7(<1)$ & \\
\hline AJCC stage, N, (\%) & & & & $<.001$ \\
\hline 1 & $1,187(35)$ & $772(38)$ & $415(30)$ & \\
\hline 11 & 1,467 (43) & $887(44)$ & $580(42)$ & \\
\hline III & $740(22)$ & $356(18)$ & $384(28)$ & \\
\hline
\end{tabular}


Table 1 Patient demographics and clinicopathological characteristics for Stage I, II, III patients with HER2-positive breast cancer (Continued)

\begin{tabular}{|c|c|c|c|c|}
\hline Histologic grade, N, (\%) & & & & $<.001$ \\
\hline Low/Intermediate & $907(27)$ & $719(36)$ & $188(14)$ & \\
\hline High & 2,324 (68) & $1,211(60)$ & $1,113(81)$ & \\
\hline Unknown & $163(5)$ & $85(4)$ & $78(6)$ & \\
\hline Histology, N, (\%) & & & & $<.001$ \\
\hline Invasive ductal & $3,101(91)$ & $1,772(88)$ & $1,329(97)$ & \\
\hline Invasive lobular & $105(3)$ & $89(4)$ & $16(1)$ & \\
\hline Mixed ductal and lobular & $139(4)$ & $120(6)$ & $19(1)$ & \\
\hline Other & $49(1)$ & $34(2)$ & $15(1)$ & \\
\hline LVI, N, (\%) & & & & 0.630 \\
\hline Presence & $1,164(34)$ & $678(34)$ & $486(35)$ & \\
\hline Absence & $2,113(62)$ & $1,267(63)$ & $846(61)$ & \\
\hline Unknown & $117(3)$ & $70(3)$ & $47(3)$ & \\
\hline EIC, N, (\%) & & & & 0.536 \\
\hline Presence & $606(18)$ & $353(18)$ & $253(18)$ & \\
\hline Absence & $2,788(82)$ & $1,662(82)$ & $1,126(82)$ & \\
\hline \multicolumn{5}{|l|}{ In patients with documented recurrence } \\
\hline Variable & $\begin{array}{l}\text { Total } \\
N=458\end{array}$ & $\begin{array}{l}\text { HR-positive } \\
N=208\end{array}$ & $\begin{array}{l}\text { HR-negative } \\
N=250\end{array}$ & $P$-value \\
\hline Disease free interval median (range), y & $1.95(7.69)$ & $2.24(7.69)$ & $1.70(7.08)$ & \\
\hline Age, mean (se), y & $50.95(0.60)$ & $50.39(0.94)$ & $51.41(0.78)$ & \\
\hline Race/Ethnicity, N, (\%) & & & & 0.644 \\
\hline African-American & $51(11)$ & $21(10)$ & $30(12)$ & \\
\hline Caucasian & $358(78)$ & $166(80)$ & $192(77)$ & \\
\hline Hispanic & $31(7)$ & $12(6)$ & $19(8)$ & \\
\hline Asian Pacific Island & $12(3)$ & $6(3)$ & $6(2)$ & \\
\hline American Indian & $1(<1)$ & $1(<1)$ & $0(0)$ & \\
\hline Other & $4(1)$ & $1(<1)$ & $3(1)$ & \\
\hline Unknown & $1(<1)$ & $1(<1)$ & $0(0)$ & \\
\hline Menopausal status at time of diagnosis of index cancer, $\mathrm{N},(\%)$ & & & & 0.207 \\
\hline Premenopausal & $223(49)$ & $108(52)$ & $115(46)$ & \\
\hline Postmenopausal & $235(51)$ & $100(48)$ & $135(54)$ & \\
\hline Co-morbidity score at time of diagnosis of index cancer, $\mathrm{N},(\%)$ & & & & 0.437 \\
\hline 0 & $371(81)$ & $166(80)$ & $205(82)$ & \\
\hline 1 & $57(12)$ & $25(12)$ & $32(13)$ & \\
\hline $2+$ & $30(7)$ & $17(8)$ & $13(5)$ & \\
\hline AJCC stage at time of diagnosis of index cancer, $\mathrm{N},(\%)$ & & & & 0.437 \\
\hline 1 & $77(17)$ & $36(17)$ & $41(16)$ & \\
\hline "l & $188(41)$ & $91(44)$ & $97(39)$ & \\
\hline III & $193(42)$ & $81(39)$ & $112(45)$ & \\
\hline Histologic grade at time of diagnosis of index cancer, $\mathrm{N},(\%)$ & & & & 0.016 \\
\hline Low/Intermediate & $65(14)$ & $40(19)$ & $25(10)$ & \\
\hline High & $379(83)$ & $163(79)$ & $216(86)$ & \\
\hline Unknown & $14(3)$ & $5(2)$ & $9(4)$ & \\
\hline
\end{tabular}

Note: AJCC, American Joint Committee on Cancer Staging; EIC, extensive intraductal component; HR, Hormone receptor; LVI, Lymphovascular invasion; se, standard error; $y$, year

Recurrence was documented in 458 women. Of these, $45 \%$ had $\mathrm{HR}+/ \mathrm{HER} 2+$ tumors and $55 \%$ had HR-/HER $2+$ tumors. A total of 32 patients experienced recurrences beyond five years (66\% HR-positive and 34\% HR-negative). At first recurrence, most (68\%) of patients received chemotherapy; $86 \%$ of these patients received concurrent 
HER2-based therapy, either trastuzumab or lapatinib (Additional file 1, Table S1).

\section{Patterns of recurrence \\ Type of first recurrence by $H R$}

At first recurrence, the risks of local vs. distant recurrence by HR status appeared similar (Table 2; Additional file 2, Table S2). Brain involvement was present in $20 \%$ of patients with documented recurrence of HR-/ HER2 + tumors and in $13 \%$ of patients with documented recurrence of HR+/HER2+ tumors (Additional file 3, Table S3). Bone disease was present in $28 \%$ of patients with $\mathrm{HR}+/ \mathrm{HER} 2+$ breast cancer and in $17 \%$ of patients with HR-/HER2+ tumors (Additional file 3, Table S3). By univariate analysis, patients with HR-negative tumors were more likely to experience brain recurrence $(\mathrm{OR}=$ 1.75, $95 \% \mathrm{CI}: 1.05$ to $2.93, P=0.033)$, and less likely to have bone recurrence $(\mathrm{OR}=0.53,95 \% \mathrm{CI}: 0.34$ to 0.82 , $P=0.005)$. After multivariable adjustment, the difference in risk of bone recurrence persisted $(\mathrm{OR}=0.53$, $95 \%$ CI: 0.34 to $0.83, P=0.005$ ); however, the difference in risk of brain recurrence was only borderline significant $(\mathrm{OR}=1.63,95 \% \mathrm{CI}: 0.95$ to $2.81, P=0.079)$. No differences in risk of lung or liver as the first site of recurrence by HR were observed (Table 2). The type of recurrence among patients with documented recurrence in the early and late recurring subgroup is represented in Additional files 4, 5, 6, 7, Tables S4-7. Overall the pattern of recurrence in the early recurring subgroup is similar to the overall cohort. In the late recurring subgroup, bone disease was present in 19\% of patients with $\mathrm{HR}+/$ HER $2+$ tumors and in $9 \%$ of patients with HR-/ HER2+ tumors. Brain involvement was present in $24 \%$ with HR+/HER $2+$ tumors and in $18 \%$ of patients with HR-/HER2+ tumors. Lung disease was present in 38\% of patients with late recurrence versus $15 \%$ in the early recurring subgroup.

\section{Type of first and subsequent recurrence by $H R$}

Combining first and subsequent sites of recurrence, brain involvement was present in $40 \%$ of patients with documented recurrence of HR-/HER2+ breast cancer and in
$33 \%$ of patients with documented recurrence of $\mathrm{HR}+1$ HER2+ tumors. Thirty-four percent of patients with HR-/ HER2 + tumors had bone recurrence compared to $49 \%$ of patients with $\mathrm{HR}+/ \mathrm{HER} 2+$ tumors. Lung involvement was present in $40 \%$ of patients with HR-/HER $2+$ tumors and in $31 \%$ of patients with HR+/HER $2+$ tumors. As such, combining first and subsequent sites of recurrence, patients with HR-negative tumors were slightly more likely to experience lung involvement $(\mathrm{OR}=1.48,95 \%$ CI: 1.00 to $2.18, P=0.05$ ) and less likely to recur in bone $(\mathrm{OR}=0.54,95 \% \mathrm{CI}: 0.37$ to $0.78, p=0.001)$. In multivariable analysis, this pattern persisted for bone recurrence $(\mathrm{OR}=0.55,95 \% \mathrm{CI}: 0.37$ to $0.80, P=0.002)$ and became even less significant for lung recurrence $(\mathrm{OR}=1.45,95 \%$ CI: 0.98 to $2.15, P=0.061$ ). No association of $\mathrm{HR}$ with brain or liver disease was found. In the multivariable model, young age (OR $=1.66,95 \% \mathrm{CI}: 1.11$ to $2.47, P=$ 0.014 ), higher stage at presentation (Stage III vs. Stage I: OR $=2.05,95 \%$ CI: 1.12 to $3.75, P=0.020)$ and adjuvant trastuzumab use $(\mathrm{OR}=1.61,95 \% \mathrm{CI}: 1.06$ to 2.46 , $P=0.025)$ were significantly associated with brain involvement when compared to other sites of recurrence. Adjuvant trastuzumab was associated with a decrease in the risk of liver recurrence vs. other sites of recurrence $(\mathrm{OR}=0.63,95 \% \mathrm{CI}: 0.41$ to $0.96, P=0.033)$. No other differences in recurrence sites with adjuvant trastuzumab were observed (Table 3; Additional files 8, 9, Tables S8, S9).

\section{Agreement between primary and metastatic samples}

Among patients with available data $(\mathrm{n}=126$ for evaluation of ER status, $\mathrm{n}=123$ for evaluation of PR status, and $\mathrm{n}=121$ for evaluation of HER2 status), ER status changed (positive to negative, or vice versa) in $22 \%$ of patients; PR status changed (positive to negative, or vice versa) in $29 \%$ of patients; HER2 status changed from positive to negative in $17 \%$ of patients. Because the cohort was defined as HER2-positive patients, we were unable to describe the number of patients whose HER2 converted from negative to positive. There was a $49 \%$ rate of any discordance within the available data (Table 4).

Table 2 Results of logistic regression for site of first (s) of recurrence

\begin{tabular}{lllll}
\hline & $\begin{array}{l}\text { Univariate analysis } \\
\text { OR }(95 \% \mathrm{Cl})\end{array}$ & $P$-value & $\begin{array}{l}\text { Multivariable analysis } \\
\text { OR (95\% CI) }\end{array}$ & $P$-value \\
\hline & $\begin{array}{l}\text { HR-negative vs. } \\
\text { HR-positive }\end{array}$ & & $\begin{array}{l}\text { HR-negative vs. } \\
\text { HR-positive }\end{array}$ & 0.531 \\
\hline $\begin{array}{l}\text { Local regional } \\
\text { vs. Distant }\end{array}$ & $1.06(0.71,1.59)$ & 0.772 & $1.15(0.75,1.76)$ & 0.079 \\
$\begin{array}{l}\text { Brain vs. Other } \\
\text { Bone vs. Other }\end{array}$ & $1.75(1.05,2.93)$ & 0.033 & $1.63(0.95,2.81)$ & 0.005 \\
$\begin{array}{l}\text { Lung vs. Other } \\
\text { Liver vs. Other }\end{array}$ & $0.53(0.34,0.82)$ & 0.005 & $0.53(0.34,0.83)$ & 0.353 \\
\hline
\end{tabular}

Note: HR, Hormone receptor. Adjusting by age at diagnosis, stage and adjuvant trastuzumab. 
Table 3 Results of logistic regression for site of first (s) and subsequent of recurrence

\begin{tabular}{lllll}
\hline & $\begin{array}{l}\text { Univariate analysis } \\
\text { OR }(\mathbf{9 5 \%} \mathrm{Cl})\end{array}$ & $P$-value & $\begin{array}{l}\text { Multivariate analysis } \\
\text { OR (95\% Cl) }\end{array}$ & $P$-value \\
\hline & HR-negative vs. positive & & HR-negative vs. positive & 0.246 \\
\hline $\begin{array}{l}\text { Local regional } \\
\text { vs. }\end{array}$ & $0.71(0.44,1.15)$ & 0.162 & $0.74(0.44,1.23)$ & \\
Distant & & & & 0.191 \\
Brain vs. Other & $1.37(0.93,2.02)$ & 0.107 & $1.31(0.88,1.95)$ & 0.002 \\
Bone vs. Other & $0.54(0.37,0.78)$ & 0.001 & $0.55(0.37,0.80)$ & 0.061 \\
Lung vs. Other & $1.48(1.00,2.18)$ & 0.050 & $1.45(0.98,2.15)$ & 0.764 \\
Liver vs. Other & $1.01(0.69,1.48)$ & 0.954 & $1.06(0.72,1.56)$ & \\
\hline
\end{tabular}

Note: HR, Hormone receptor. Adjusting by age at diagnosis, stage and adjuvant trastuzumab.

\section{Survival outcomes}

Among 3,394 patients, death was recorded in $13 \%$ of patients $(\mathrm{N}=457)$, and breast-cancer specific death in $10 \%$ of patients $(\mathrm{N}=337)$. The risk of death was not proportional over time for HR status and time dependent covariates yielded patients with HR-negative tumors having significantly increased hazard in the first five years (hazard ratio of death zero to two years = 1.92, 95\% CI: 1.28 to $2.86, P=0.002$; hazard ratio of death two to five years $=1.55,95 \% \mathrm{CI}: 1.19$ to $2.00, P=$ 0.001 ; hazard ratio of death more than five years $=0.81$, 95\% CI: 0.55 to $1.19, P=0.285$ ) (Figure 1 ). Similar results were seen for BCSS (data not shown).

HR-negative status and lack of adjuvant trastuzumab were associated with increased hazards. The hazards for patients with HR-negative tumors who did not receive adjuvant trastuzumab (median survival for HR-negative tumors that did not receive trastuzumab: 4.48 years) were amplified when compared to patients with HRpositive tumors who received trastuzumab (median survival for HR-positive tumors that received trastuzumab: 8.43 years) (Figure 2).

\section{Discussion}

In this large cohort of patients with Stage I to III HER2positive breast cancer, we found significant associations between HR status and presenting features, patterns of recurrence and survival outcomes. As compared with patients with HR-positive tumors, those with HR-negative tumors were less likely to recur in bone. In addition, $20 \%$ of patients with HR-negative tumors recurred first in the brain compared with $13 \%$ of HR-positive patients. Moreover, HR-negative patients experienced more deaths in the first five years, compared with HRpositive patients, but no statistically significant differences in hazards of death beyond Year 5 were found.

Our studies confirm other studies regarding the impact of HR status on sites of recurrence in HER2 disease [13,21-23]. Non-overlapping organ-specific signatures of recurrence in breast cancer have previously been recognized. Moreover, molecular subtypes have been associated with preferential sites of relapse. For instance, in the luminal subtypes (HR-positive subtypes) bone relapse is frequent and brain relapse is usually less common [24-29]. In our study, this pattern of recurrence was also found in the HR+/HER $2+$ tumors. Our results suggest that HR status remains a major driver of clinical phenotype, even among HER2-positive patients.

Due to the small number of patients with late recurrence, we cannot draw definitive conclusions about recurrence patterns by HR in patients with early versus late recurrences and, therefore, our results are only

Table 4 Agreement between HR and HER2 status from primary and metastatic samples

\begin{tabular}{|c|c|c|c|c|c|c|}
\hline & HR status* & & & & HER2* & \\
\hline & ER status & $\begin{array}{l}\text { K } \\
\text { (ASE) }\end{array}$ & PR status & $\begin{array}{l}\mathrm{K} \\
\text { (ASE) }\end{array}$ & HER2 Status & $\begin{array}{l}\mathrm{K} \\
\text { (ASE) }\end{array}$ \\
\hline Total (N) & 126 & & 123 & & 121 & \\
\hline \multicolumn{7}{|c|}{$\begin{array}{l}\text { Agreement, } \\
\mathrm{N}(\%)\end{array}$} \\
\hline Yes & $98(78)$ & $0.55(0.074)$ & $86(70)$ & $0.31(0.083)$ & $101(83)$ & $\begin{array}{l}0.003 \\
(0.019)\end{array}$ \\
\hline No & $28(22)$ & & & $37(29)$ & & $20(17)$ \\
\hline+ to - & $18(14)$ & & & $30(24)$ & & $20(17)$ \\
\hline - to + & $10(8)$ & & & $7(6)$ & & N/A \\
\hline
\end{tabular}

Note: + to - , change from positive to negative marker; - to +, change from negative to positive marker; ER, estrogen receptor; HER2, Human epidermal growth factor 2; HR, Hormone receptor; PR, progesterone receptor. *Data were available in a limited number of samples due to unknown information in the metastatic setting. 


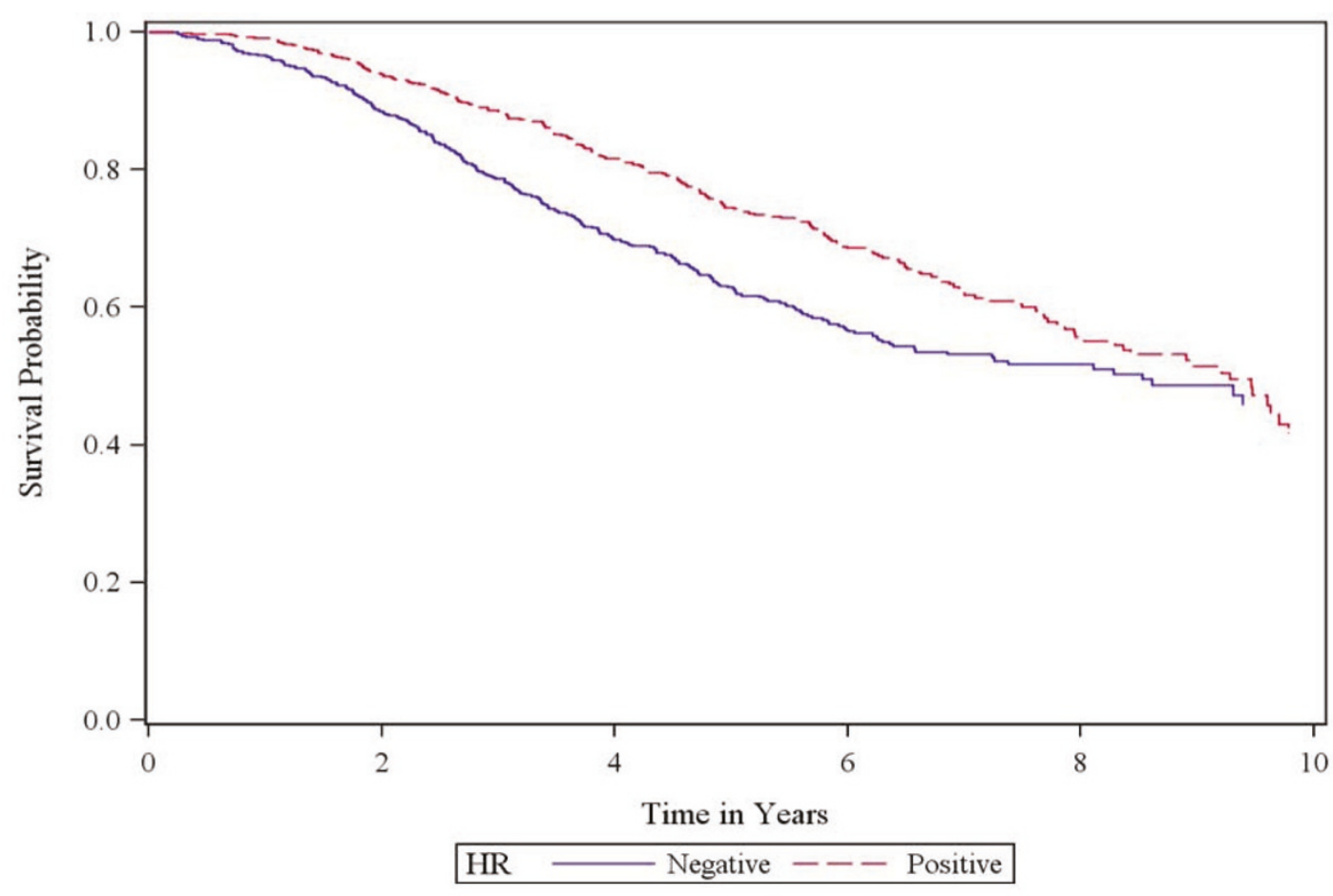

Number at risk

\begin{tabular}{lrrrrrr}
\hline HR-positive & 2,015 & 1,924 & 1,391 & 756 & 308 & 100 \\
HR-negative & 1,379 & 1,280 & 910 & 475 & 256 & 77
\end{tabular}

Hazard Ratio $(95 \% \mathrm{Cl})$

HR-negative vs. HR-positive

\begin{tabular}{lll}
\hline $\mathbf{0 - 2}$ years & $1.92(1.28,2.86)$ & 0.002 \\
$\mathbf{2 - 5}$ years & $1.55(1.19,2.00)$ & 0.001 \\
$>\mathbf{5}$ years & $0.81(0.55,1.19)$ & 0.285
\end{tabular}

Figure 1 Overall survival since time of diagnosis by HR status. Note: HR, Hormone receptor. Adjusted by age, race/ethnicity, stage at diagnosis, grade and year of diagnosis.

hypothesis-generating. A total of $38 \%$ of patients in the late recurring subgroup relapsed in the lung, with no apparent difference according to HR status; whereas 15\% of patients in the early recurring group had recurrence in the lung (including 13\% of HR-positive patients and 18\% of HR-negative patients). In the early recurrence subgroup, HR-negative patients seemed to be more likely to experience brain relapse as the first site of recurrence compared with HR-positive patients. This difference appears to disappear in the late recurring subgroup. It would be of potential interest to explore other datasets to determine if these findings are consistent across studies.
Overall, the incidence of brain metastasis in HER2positive disease has been described as 25 to 55\% [30-33]. Some, but not all, studies have reported differences in the frequency of brain metastases according to HR status. Kennecke et al. reported a frequency of $29 \%$ in HR-/ HER2 + disease compared with $15 \%$ in HR+/HER2+ disease [13]. Brufsky et al. reported frequencies of $44 \%$ and $31 \%$, respectively, among patients with either HR-/HER2+ disease, compared with HR+/HER2+ disease [33].

In the adjuvant trastuzumab trials in HER2-positive disease, the overall risk of brain recurrence was small (NSABP B-31/NCCTG N9831 trials: 1\%, HERA trial: 


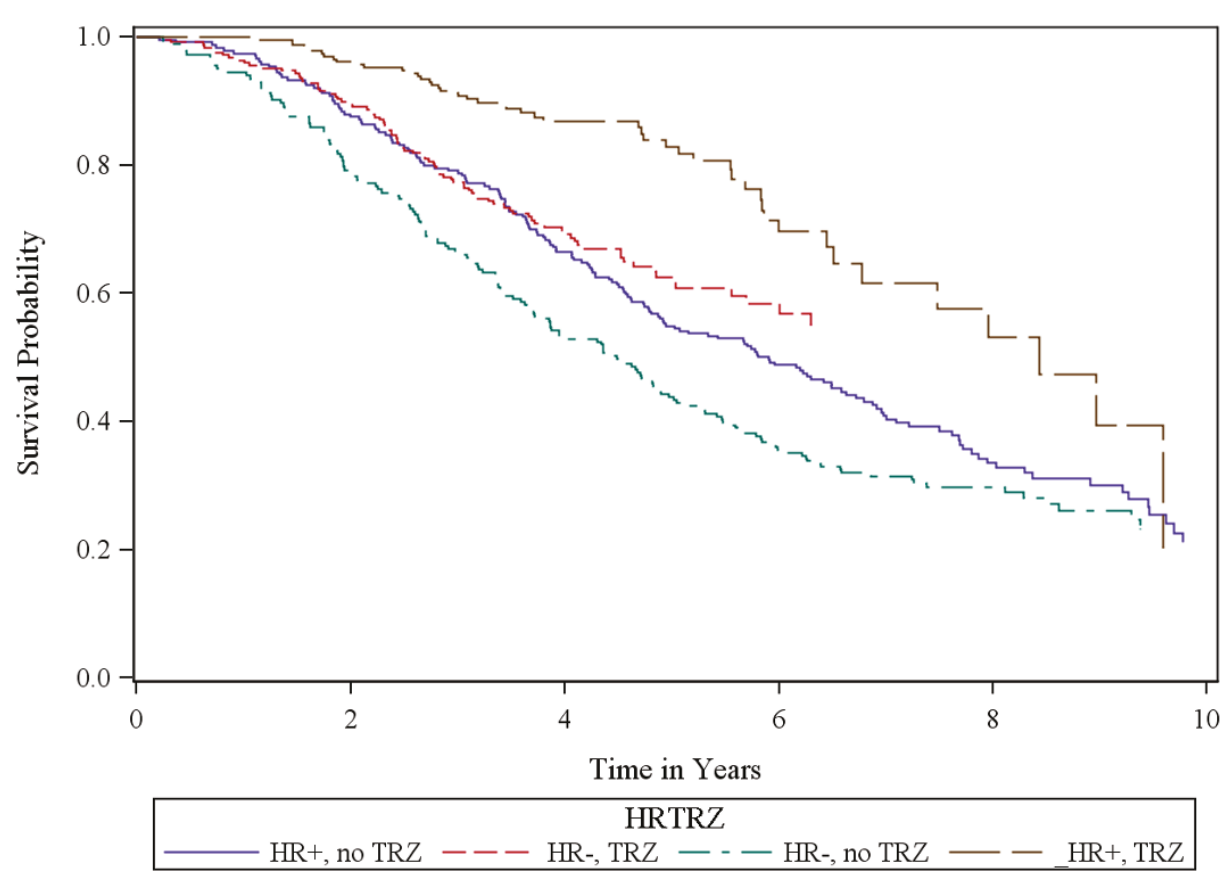

Number at risk

\begin{tabular}{lrrrrrr}
\hline HR-positive TRZ & 837 & 811 & 478 & 143 & 43 & 8 \\
HR-negative TRZ & 665 & 625 & 390 & 136 & & \\
HR-positive No TRZ & 1,178 & 1,115 & 926 & 617 & 266 & 93 \\
HR-negative No TRZ & 714 & 656 & 521 & 349 & 215 & 68
\end{tabular}

\begin{tabular}{|c|c|c|c|c|c|c|}
\hline & Hazard Ratio (95\% Cl) & $P$-value & Hazard Ratio $(95 \% \mathrm{Cl})$ & $P$-value & Hazard Ratio (95\% Cl) & $P$-value \\
\hline & $\begin{array}{l}\text { HR-negative } \\
\text { TRZ }\end{array}$ & & $\begin{array}{l}\text { HR-positive } \\
\text { No TRZ }\end{array}$ & & $\begin{array}{l}\text { HR-negative } \\
\text { No TRZ }\end{array}$ & \\
\hline $0-2$ years & $2.84(1.33,6.06)$ & 0.007 & $3.42(1.59,7.36)$ & 0.002 & $6.01(2.83,12.81)$ & $<.001$ \\
\hline $2-5$ years & $2.58(1.59,4.20)$ & $<.001$ & $3.07(1.87,5.03)$ & $<.001$ & $3.97(2.40,6.57)$ & $<.001$ \\
\hline$>5$ years & $0.41(0.16,1.05)$ & 0.064 & $0.98(0.56,1.72)$ & 0.952 & $0.93(0.52,1.67)$ & 0.806 \\
\hline \multicolumn{7}{|c|}{$\begin{array}{l}\text { Figure } 2 \text { Overall survival since time of diagnosis by HR status and receipt adjuvant trastuzumab. Note: Reference group are those who } \\
\text { are HR positive and received Trastuzumab. HR, Hormone receptor; TRZ, Trastuzumab. Adjusted by age, race/ethnicity, stage at diagnosis, grade } \\
\text { and year of diagnosis. }\end{array}$} \\
\hline
\end{tabular}

$1 \%)$; however, the brain represented an important proportion of the sites for first recurrences (NSABP B-31/ NCCTG N9831 trial: 18\%, HERA trial: 10\%) [34,35].

Similarly, in our study, $20 \%$ of first recurrences in patients with HR-negative tumors and 13\% of first recurrences in HR-positive patients occurred in the brain. Combining first and subsequent sites of recurrence, $40 \%$ of $\mathrm{HR}$-negative patients and $33 \%$ of HR-positive patients had brain involvement. The most striking differences were found in the incidence of the brain as the site of first recurrence, with differences between the groups attenuating over time and after adjusting to clinicopathological factors. Similar to previous findings, young age, higher presenting stage and adjuvant trastuzumab use were associated with a higher likelihood of brain recurrence [36].

It is notable that previous efforts to define a gene signature predictive of central nervous system (CNS) relapse among patients with HER2-positive disease did not succeed in identifying a predictor of the presence or absence of CNS relapse, but were successful in distinguishing between those patients with early versus late brain relapse [37]. Our data support the hypothesis that biologic factors predisposing to early brain relapse are probably not the same as those predisposing to later CNS involvement. Moreover, within the subgroup of patients 
with early relapses, $20 \%$ of HR-negative patients had the brain as the first site of recurrence versus $11 \%$ of HRpositive patients; within the subgroup of patients with late relapses, $18 \%$ of patients had the brain as the first site of recurrence versus $24 \%$ of HR-positive patients.

Multiple prior studies have described differences in the hazard of relapse and death over time according to HR status [20,38]. We found that HR status is also associated with the hazard of death over time within the HER2-positive population. Patients with HR-/HER2+ tumors faced a higher risk of death within five years of initial diagnosis; however, beyond five years no statistically significant differences in hazards of death between groups were found. Similar results can be observed when observing the shape of the survival curves in the adjuvant trials. For example, both in the CALGB9344/ INT0148 and in the HERA trial this difference in the hazard of relapse over time is apparent $[12,15]$.

Concordant with previous knowledge, trastuzumab increases the rates of survival independently of HR status. After stratifying by adjuvant trastuzumab use, the differences in survival by HR status persisted. It is worth noting that despite a lower rate of pathologic complete responses ( $\mathrm{pCR}$ ) among patients with $\mathrm{HR}+/ \mathrm{HER} 2+$ tumors across neoadjuvant trials [10,39-45], the overall prognosis of such patients is not worse than those with HR-/HER2+ tumors. These findings also suggest that in patients with $\mathrm{HR}+/ \mathrm{HER} 2+$ tumors, lack of $\mathrm{pCR}$ will, potentially, have less prognostic value than among patients with HR-/HER2+ tumors [46].

Finally, we explored the agreement in ER, PR and HER2 between primary and metastatic biopsies. Previous studies showed that discordance rates between primary and metastatic samples range between $10 \%$ and $40 \%$. Discordance may be associated with: a) methodological factors, b) intratumoral heterogeneity and c) clonal selection associated with adjuvant therapy. The relative contribution of each of these factors is not determined, although it is believed that a true switch in biology should be a rare event [47]. We found a $49 \%$ rate of any discordance between primary and metastatic samples, including a switch from HER2-positive to HER2-negative in $17 \%$ of cases. The influence of neoadjuvant chemotherapy plus trastuzumab on HER2 has been investigated, with a loss of HER2 amplification/overexpression in $12 \%$ to $43 \%$ of the cases with residual disease [48]. Previous studies suggested that discordance between primary and metastatic samples can have prognostic value $[49,50]$, and further investigation of the biologic, prognostic and predictive value of the discordance between primary and metastatic samples is warranted.

Our study had a number of strengths. We had access to a large prospectively collected dataset which drew from large centers distributed geographically across the
U.S. Because the sample was limited to patients who initially presented with early stage disease, we could adjust for clinically relevant tumor- and treatmentrelated variables. Unlike the majority of adjuvant trials, we captured all sites of both first and subsequent recurrence, and thus were able to provide a broader picture of the natural history of HER2-positive disease. In addition, analysis of metastatic patterns in our study was less biased than if we had relied on clinical trials in the metastatic setting, where inclusion/exclusion criteria could introduce significant selection bias (for example, restrictions on patients with brain metastases, elevated liver function tests, and so on). Finally, by only including patients with metastatic disease who were initially seen at time of early stage diagnosis, we hoped to minimize potential referral bias, which is a valid concern given the nature of the NCCN participating institutions. For instance, patients referred to an NCCN center for the first time to consider a third-line chemotherapy trial would not be included in this dataset.

Our study also had several limitations. HR status was based on the assessment provided by the breast cancer pathologists at the time of diagnosis. We did not conduct central pathologic review of the tumor samples nor did we require uniform pre-specified cut-offs for these markers. The classification was based on the standards used in each center applicable at the time of diagnosis. It is likely that academic pathologists at the participating NCCN institutions reviewed specimens as part of routine clinical care, which is reassuring as to the quality of the information provided. However, we acknowledge the potential for some difference in interpretation over time, particularly in the setting of low-level $(<10 \%)$ expression.

Because the study was limited to patients who presented to NCCN centers, we cannot rule out a potential referral bias. However, it is unlikely that the impact of HR in HER2 disease would be different in a populationbased sample, and our data are consistent with other published data of the impact of HR status in HER2-positive disease. Patients received a variety of neoadjuvant and adjuvant therapies and, as expected, the use of trastuzumab increased over time. However, results were not materially different after adjusting for the use of trastuzumab, suggesting that our findings regarding recurrence patterns are relevant to current practice.

With respect to our analysis of discordance in HR and HER2 between primary and metastatic samples, we did not conduct central pathologic review of the tumor samples, and cannot rule out technical issues as a cause of discordance. However, as previously noted, it is likely that almost all specimens were reviewed as part of routine clinical care at the participating NCCN academic institutions.

Finally, we used classical pathological markers (ER/PR and HER2) as a proxy for the intrinsic subtypes. For 
practical purposes, it is generally accepted that intrinsic subtypes are approximated using clinicopathological criteria $[7,51]$. However, several groups have reported varying levels of concordance between assignments of subtype by IHC and gene expression array criteria, and most suggest that the information provided by the molecular subtypes expands the information provided by classical clinicopathologic markers. A combined dataset that included 106 patients that belong to the HER2 enriched subtype, comprised 51\% ER-negative/HER2positive, 15\% ER-positive/HER2-positive and even 34\% HER2-negative analyzed by classical procedures. In a different report, all patients that belong to HER2-like molecular subtype were HER2-positive, 46\% ER-positive $[7,52]$. It is conceivable that using gene expression profiling to classify tumors may have resulted in more dramatic differences in the patterns of recurrence and survival outcomes over time.

\section{Conclusions}

Our study supports the classification of HER2 disease as two different entities distinguished by HR. Further work to understand the relationship between intrinsic subtype and outcomes restricted to patients with clinically HER2-positive disease is warranted. We believe this has implications in both basic and clinical research. In particular, we believe that the next generation of HER2focused clinical trials should integrate HR status (and/or intrinsic subtype) in their design, either by designing distinct treatment protocols for patients with HR +/HER2+ disease compared to HR-/HER2+ disease, or by allocating patients within strata defined by $H R$.

\section{Additional material}

Additional file 1: Table S1. Treatment characteristics. Treatment characteristics at the time of diagnosis and at the time of first recurrence. Note: HR, Hormone receptor.

Additional file 2: Table S2. Type of first (s) recurrence by HR among patients with documented recurrence - type of site of first(s) recurrence date. Type of site of first(s) recurrence (local/regional, distant, combined) by HR among patients with documented recurrence.

Additional file 3: Table S3. Type of first (s) recurrence by HR among patients with documented recurrence - type of site diagnosed on first recurrence(s) date. Type of site of first(s) recurrence (ipsilateral breast, chest wall/local nodes/regional nodes, contralateral breast, bone, lung, liver, brain, all other sites) by HR among patients with documented recurrence. * Analysis based on cohort of 458 patients (208, HR positive; 250 , HR negative) with documented recurrence, representing a total of 553 sites of recurrence. Proportion of patients does not add up to $100 \%$ as patients could have more than one site of recurrence.

Additional file 4: Table S4. Type of first (s) recurrences by HR among patients with documented recurrence - type of first(s) recurrences in the early recurring subgroup. Type of site of first(s) recurrence (local/regional, distant, combined) by HR among patients with documented early recurrence.

Additional file 5: Table S5. Type of first (s) recurrences by HR among patients with documented recurrence - type of site diagnosed on first(s) recurrences in the early recurring subgroup Type of site of first(s) recurrence (ipsilateral breast, chest wall/local nodes/ regional nodes, contralateral breast, bone, lung, liver, brain, all other sites) by HR among patients with documented early recurrence.* Analysis based on cohort of 426 patients (187, HR positive; 239, HR negative) with documented recurrence, representing a total of 515 sites of recurrence. Proportion of patients does not add up to $100 \%$ as patients could have more than one site of recurrence

Additional file 6: Table S6. Type of first (s) recurrences by HR among patients with documented recurrence - type of first(s) recurrences in the late recurring subgroup. Type of site of first(s) recurrence (local/regional, distant, combined) by HR among patients with documented late recurrence.

Additional file 7: Table S7. Type of first (s) recurrences by HR among patients with documented recurrence - type of site diagnosed on first(s) recurrences in the late recurring subgroup.

Type of site of first(s) recurrence (ipsilateral breast, chest wall/local nodes/ regional nodes, contralateral breast, bone, lung, liver, brain, all other sites) by HR among patients with documented late recurrence. *Analysis based on cohort of 32 patients (21, HR positive; 11 , HR negative) with documented recurrence, representing a total of 38 sites of recurrence. Proportion of patients does not add up to $100 \%$ as patients could have more than one site of recurrence.

Additional file 8: Table S8. Type of first (s) and subsequent recurrences by HR among patients with documented recurrencetype of first(s) and subsequent recurrences. Type of site of first(s) and subsequent recurrence (local/regional, distant, combined) by HR among patients with documented recurrence.

Additional file 9: Table S9. Type of first (s) and subsequent recurrences by HR among patients with documented recurrencetype of site diagnosed on first(s) and subsequent recurrences. Type of site of first(s) recurrence (ipsilateral breast, chest wall/local nodes/ regional nodes, contralateral breast, bone, lung, liver, brain, all other sites) by HR among patients with documented recurrence. *Analysis based on cohort of 458 patients (208, HR positive; 250, HR negative) with documented recurrence, representing a total of 1,014 sites of recurrence. Proportion of patients does not add up to $100 \%$ as patients could have more than one site of recurrence.

\section{Abbreviations}

AJCC: American Joint Committee on Cancer; ASE: asymptotic standard error; BCSS: Breast Cancer Specific Survival; BMI: body mass index; CNS: central nervous system; ElC: extensive intraductal component; ER: estrogen receptor; FISH: Fluorescence in situ hybridization; HER-2: Human epidermal growth factor-2; HR: Hormone receptor; HR+/HER2+: HR-positive/HER2-positive; HR-/ HER2+HR-negative/HER2-positive; IHC: Immunohistochemistry; LVI: Lymphovascular invasion; NCCN: National Comprehensive Network; NDI: National Death Index; OR: odds ratio; OS: overall survival: PCR: pathologic complete response; PR: progesterone receptor;

\section{Acknowledgements}

The authors acknowledge the National Cancer Institute Specialized Program of Research Excellence in Breast Cancer (NIH P50 CA089393); National Comprehensive Cancer Network; Breast Cancer Research Foundation; Karen Webster and David Evans Research Fund. This work was conducted with the support from the Scholars in Clinical Science Program of Harvard Catalyst I The Harvard Clinical and Translational Science Center (Award No. UL1 RR025758 and financial contributions from Harvard University and its affiliated academic health care centers). The content is solely the responsibility of the authors and does not necessarily represent the official views of Harvard Catalyst, Harvard University and its affiliated academic health care centers, the National Center for Research Resources, or the National Institutes of Health. IVL is supported by FCT (HMSP-ICS/0004/2011). The study was supported by the National Cancer Institute Specialized Program of Research Excellence in Breast Cancer (NIH P50 CA089393), the National Comprehensive Cancer Network, Breast Cancer Research Foundation (to NUL), American Society of Clinical Oncology Cancer 
Foundation (Career Development Award to NUL), Berry Junior Faculty Award (to NUL), and the Karen Webster and David Evans Research Fund.

\section{Author details}

'Department of Medical Oncology, Dana-Farber Cancer Institute, Boston, MA USA. ${ }^{2}$ Clinical and Translational Oncology Research Unit, Instituto de Medicina Molecular, Lisbon, Portugal. ${ }^{3}$ Department of Information Sciences, City of Hope Comprehensive Cancer Center, Duarte, CA, USA. ${ }^{4}$ Department of Medical Oncology, Duke University Medical Center, Durham, NC, USA. ${ }^{5}$ Department of Medicine, Massachusetts General Hospital, Boston, MA, USA. ${ }^{6}$ Department of Medicine, San Francisco Helen Diller Family Comprehensive Cancer Center, San Francisco, CA, USA. ${ }^{7}$ Department of Breast Medical Oncology, University of Texas M. D. Anderson Cancer Center, Houston, TX, USA. ${ }^{8}$ Department of Internal Medicine, Arthur G. James Cancer Hospital, Ohio State University, Columbus, OH, US

\section{Authors' contributions}

IVL and NUL conceived the study and the design of the study, participated in the analysis and interpretation of the data, and coordinated and drafted the manuscript. RAO participated in the design of the study, performed the statistical analysis, participated in the interpretation of the data and helped in drafting the manuscript. MEH participated in the design of the study, statistical analysis, interpretation of the data, coordination and helped in drafting the manuscript. JCW participated in the design of the study, interpretation of the data, coordination, and helped in drafting the manuscript. PKM, BM, HSR, RLT, JW and JCN participated in the interpretation of the data and helped in drafting the manuscript. All authors read and approved the final manuscript.

\section{Competing interests}

$\mathrm{BM}$ is an uncompensated consultant or has an uncompensated advisory role for GlaxoSmithKline and Pfizer. RLT has stock ownership in UpToDate, NUL receives Research Funding from Genentech, GlaxoSmithKline, Infinity Pharmaceuticals, Boehringer Ingelheim, and has a consultant or advisory role for GlaxoSmithKline (compensated), Novartis (compensated) and Genentech (uncompensated). IVL, RAO, MEH, PKM, HSR, JW, JCN and JCW declare that they have no competing interests.

Received: 2 June 2012 Revised: 25 July 2012 Accepted: 1 October 2012 Published: 1 October 2012

\section{References}

1. Perou CM, Sorlie T, Eisen MB, van de Rijn M, Jeffrey SS, Rees CA, Pollack JR, Ross DT, Johnsen $\mathrm{H}$, Akslen LA, Fluge O, Pergamenschikov A, Williams C, Zhu SX, Lønning PE, Børresen-Dale AL, Brown PO, Botstein D: Molecular portraits of human breast tumours. Nature 2000, 406:747-752.

2. Sotiriou C, Neo SY, McShane LM, Korn EL, Long PM, Jazaeri A, Martiat P, Fox SB, Harris AL, Liu ET: Breast cancer classification and prognosis based on gene expression profiles from a population-based study. Proc Natl Acad Sci USA 2003, 100:10393-10398.

3. van 't Veer $L$, Dai $H$, van de Vijver MJ, He YD, Hart AA, Mao M, Peterse $H L$, van der Kooy K, Marton MJ, Witteveen AT, Schreiber GJ, Kerkhoven RM, Roberts C, Linsley PS, Bernards R, Friend SH: Gene expression profiling predicts clinical outcome of breast cancer. Nature 2002, 415:530-536.

4. Prat A, Parker JS, Karginova O, Fan C, Livasy C, Herschkowitz JI, He X, Perou CM: Phenotypic and molecular characterization of the claudin-low intrinsic subtype of breast cancer. Breast Cancer Res 2010, 12:R68.

5. Sorlie T, Perou CM, Tibshirani R, Aas T, Geisler S, Johnsen H, Hastie T, Eisen MB, van de Rijn M, Jeffrey SS, Thorsen T, Quist H, Matese JC, Brown PO, Botstein D, Lønning PE, Børresen-Dale AL: Gene expression patterns of breast carcinomas distinguish tumor subclasses with clinical implications. Proc Natl Acad Sci USA 2001, 98:10869-10874.

6. Hu Z, Fan C, Oh DS, Marron JS, He X, Qaqish BF, Livasy C, Carey LA, Reynolds E, Dressler L, Nobel A, Parker J, Ewend MG, Sawyer LR, Wu J, Liu Y, Nanda R, Tretiakova M, Ruiz Orrico A, Dreher D, Palazzo JP, Perreard L, Nelson E, Mone M, Hansen H, Mullins M, Quackenbush JF, Ellis MJ, Olopade OI, Bernard PS, et al: The molecular portraits of breast tumors are conserved across microarray platforms. BMC Genomics 2006, 7:96.

7. Sotiriou C, Pusztai L: Gene-expression signatures in breast cancer. N Engl J Med 2009, 360:790-800.
8. Baselga J, Bradbury I, Eidtmann H, Di Cosimo S, de Azambuja E, Aura C, Gomez H, Dinh P, Fauria K, Van Dooren V, Aktan G, Goldhirsch A Chang TW, Horváth Z, Coccia-Portugal M, Domont J, Tseng LM, Kunz G, Sohn JH, Semiglazov V, Lerzo G, Palacova M, Probachai V, Pusztai L, Untch M, Gelber RD, Piccart-Gebhart M, NeoALTTO Study Team: Lapatinib with trastuzumab for HER2-positive early breast cancer (NeoALTTO): a randomised, open-label, multicentre, phase 3 trial. Lancet 2012, 379:633-640.

9. Gianni L, Pienkowski T, Im YH, Roman L, Tseng LM, Liu MC, Lluch A Staroslawska E, de la Haba-Rodriguez J, Im SA, Pedrini JL, Poirier B, Morandi P, Semiglazov V, Srimuninnimit V, Bianchi G, Szado T, Ratnayake J, Ross $G$, Valagussa P : Efficacy and safety of neoadjuvant pertuzumab and trastuzumab in women with locally advanced, inflammatory, or early HER2-positive breast cancer (NeoSphere): a randomised multicentre, open-label, phase 2 trial. Lancet Oncol 2011, 13:25-32.

10. Gianni L, Eiermann W, Semiglazov V, Manikhas A, Lluch A, Tjulandin S, Zambetti M, Vazquez F, Byakhow M, Lichinitser M, Climent MA, Ciruelos E, Ojeda B, Mansutti M, Bozhok A, Baronio R, Feyereislova A, Barton C, Valagussa P, Baselga J: Neoadjuvant chemotherapy with trastuzumab followed by adjuvant trastuzumab versus neoadjuvant chemotherapy alone, in patients with HER2-positive locally advanced breast cancer (the NOAH trial): a randomised controlled superiority trial with a parallel HER2-negative cohort. Lancet 2010, 375:377-384.

11. von Minckwitz G, Untch M, Blohmer J-U, Costa S-D, Eidtmann H, Fasching PA, Gerber B, Eiermann W, Hilfrich J, Huober J, Jackisch C, Kaufmann M, Konecny G, Denkert C, Nekljudova V, Mehta K, Loibl S, for the GBG and AGO-B study groups: Definition and impact of pathological complete response on prognosis after neoadjuvant chemotherapy in various intrinsic breast cancer subtypes. J Clin Oncol 2012, 30:1796-804.

12. Untch M, Gelber RD, Jackisch C, Procter M, Baselga J, Bell R, Cameron D, Bari M, Smith I, Leyland-Jones B, de Azambuja E, Wermuth P, Khasanov R, Feng-Yi F, Constantin C, Mayordomo JI, Su CH, Yu SY, Lluch A, SenkusKonefka E, Price C, Haslbauer F, Suarez Sahui T, Srimuninnimit V, Colleoni M, Coates AS, Piccart-Gebhart MJ, Goldhirsch A, HERA Study Team: Estimating the magnitude of trastuzumab effects within patient subgroups in the HERA trial. Ann Oncol 2008, 19:1090-1096.

13. Kennecke H, Yerushalmi R, Woods R, Cheang MC, Voduc D, Speers CH, Nielsen TO, Gelmon K: Metastatic behavior of breast cancer subtypes. J Clin Oncol 2010, 28:3271-3277.

14. Park YH, Lee S, Cho EY, Choi YL, Lee JE, Nam SJ, Yang JH, Ahn JS, Im YH: Patterns of relapse and metastatic spread in HER2-overexpressing breast cancer according to estrogen receptor status. Cancer Chemother Pharmacol 2010, 66:507-516.

15. Hayes DF, Thor AD, Dressler LG, Weaver D, Edgerton S, Cowan D, Broadwater G, Goldstein LJ, Martino S, Ingle JN, Henderson IC, Norton L, Winer EP, Hudis CA, Ellis MJ, Berry DA, Cancer and Leukemia Group B (CALGB) Investigators: HER2 and response to paclitaxel in node-positive breast cancer. N Engl J Med 2007, 357:1496-1506.

16. Brufsky A, Lembersky B, Schiffman K, Lieberman G, Paton VE: Hormone receptor status does not affect the clinical benefit of trastuzumab therapy for patients with metastatic breast cancer. Clin Breast Cancer 2005, 6.247-252

17. Weeks JC: Outcomes assessment in the NCCN. Oncology (Williston Park) 1997, 11:137-140.

18. Punglia RS, Hughes ME, Edge SB, Theriault RL, Bookman MA, Wilson JL, Ottesen RA, Niland JC, Weeks JC: Factors associated with guidelineconcordant use of radiotherapy after mastectomy in the National Comprehensive Cancer Network. Int J Radiat Oncol Biol Phys 2008, 72:1434-1440

19. Charlson ME, Pompei P, Ales KL, MacKenzie CR: A new method of classifying prognostic comorbidity in longitudinal studies: development and validation. J Chronic Dis 1987, 40:373-383.

20. Saphner T, Tormey DC, Gray R: Annual hazard rates of recurrence for breast cancer after primary therapy. J Clin Oncol 1996, 14:2738-2746.

21. Hess KR, Pusztai L, Buzdar AU, Hortobagyi GN: Estrogen receptors and distinct patterns of breast cancer relapse. Breast Cancer Res Treat 2003, 78:105-118.

22. Maki DD, Grossman RI: Patterns of disease spread in metastatic breast carcinoma: influence of estrogen and progesterone receptor status. AJNR: Am J Neuroradiol 2000, 21:1064-1066. 
23. Paluch-Shimon S, Ben-Baruch N, Wolf I, Zach L, Kopolovic J, Kruglikova A, Modiano T, Yosepovich A, Catane R, Kaufman B: Hormone receptor expression is associated with a unique pattern of metastatic spread and increased survival Among HER2-overexpressing breast cancer patients. Am J Clin Oncol 2009, 32:504-508.

24. Kang Y, Siegel PM, Shu W, Drobnjak M, Kakonen SM, Cordon-Cardo C, Guise TA, Massague J: A multigenic program mediating breast cancer metastasis to bone. Cancer Cell 2003, 3:537-549.

25. Minn AJ, Gupta GP, Siegel PM, Bos PD, Shu W, Giri DD, Viale A, Olshen AB, Gerald WL, Massague J: Genes that mediate breast cancer metastasis to lung. Nature 2005, 436:518-524.

26. Bos PD, Zhang XH, Nadal C, Shu W, Gomis RR, Nguyen DX, Minn AJ, van de Vijver MJ, Gerald WL, Foekens JA, Massaqué J: Genes that mediate breast cancer metastasis to the brain. Nature 2009, 459:1005-1009.

27. Smid M, Wang Y, Klijn JG, Sieuwerts AM, Zhang Y, Atkins D, Martens JW, Foekens JA: Genes associated with breast cancer metastatic to bone. J Clin Oncol 2006, 24:2261-2267.

28. Klein A, Olendrowitz C, Schmutzler R, Hampl J, Schlag PM, Maass N, Arnold N, Wessel R, Ramser J, Meindl A, Scherneck S, Seitz S: Identification of brain- and bone-specific breast cancer metastasis genes. Cancer Lett 2009, 276:212-220

29. Smid M, Wang Y, Zhang Y, Sieuwerts AM, Yu J, Klijn JG, Foekens JA, Martens JW: Subtypes of breast cancer show preferential site of relapse. Cancer Res 2008, 68:3108-3114.

30. Clayton AJ, Danson S, Jolly S, Ryder WD, Burt PA, Stewart AL, Wilkinson PM, Welch RS, Magee B, Wilson G, Howell A, Wardley AM: Incidence of cerebral metastases in patients treated with trastuzumab for metastatic breast cancer. Br J Cancer 2004, 91:639-643.

31. Bendell JC, Domchek SM, Burstein HJ, Harris L, Younger J, Kuter I, Bunnell C, Rue M, Gelman R, Winer E: Central nervous system metastases in women who receive trastuzumab-based therapy for metastatic breast carcinoma. Cancer 2003, 97:2972-2977.

32. Olson EM, Najita JS, Sohl J, Arnaout A, Winer EP, Lin NU: Predictors of survival in patients with HER2+ metastatic breast cancer (MBC) treated with trastuzumab [abstract] ASCO Meeting Abstracts. J Clin Oncol, 2011 2011, 29:e11100

33. Brufsky AM, Mayer M, Rugo HS, Kaufman PA, Tan-Chiu E, Tripathy D, Tudor IC, Wang LI, Brammer MG, Shing M, Yood MU, Yardley DA: Central nervous system metastases in patients with HER2-positive metastatic breast cancer: incidence, treatment, and survival in patients from registHER. Clin Cancer Res 2011, 17:4834-4843.

34. Romond EH, Perez EA, Bryant J, Suman VJ, Geyer CE Jr, Davidson NE, TanChiu E, Martino S, Paik S, Kaufman PA, Swain SM, Pisansky TM, Fehrenbacher L, Kutteh LA, Vogel VG, Visscher DW, Yothers G, Jenkins RB, Brown AM, Dakhil SR, Mamounas EP, Lingle WL, Klein PM, Ingle JN, Wolmark N: Trastuzumab plus adjuvant chemotherapy for operable HER2-positive breast cancer. N Engl J Med 2005, 353:1673-1684.

35. Piccart-Gebhart MJ, Procter M, Leyland-Jones B, Goldhirsch A, Untch M, Smith I, Gianni L, Baselga J, Bell R, Jackisch C, Cameron D, Dowsett M, Barrios CH, Steger G, Huang CS, Andersson M, Inbar M, Lichinitser M, Láng I, Nitz U, Iwata H, Thomssen C, Lohrisch C, Suter TM, Rüschoff J, Suto T, Greatorex V, Ward C, Straehle C, McFadden E, Dolci MS, Gelber RD, Herceptin Adjuvant (HERA) Trial Study Team: Trastuzumab after adjuvant chemotherapy in HER2-positive breast cancer. N Engl J Med 2005, 353:1659-1672.

36. Pestalozzi BC, Zahrieh D, Price KN, Holmberg SB, Lindtner J, Collins J, Crivellari D, Fey MF, Murray E, Simoncini E, Castiglione-Gertsch M, Gelber RD, Coates AS, Goldhirsch A, International Breast Cancer Study Group: Identifying breast cancer patients at risk for central nervous system (CNS) metastases in trials of the International Breast Cancer Study Group (IBCSG). Ann Oncol 2006, 17:935-944

37. Duchnowska R, Jassem J, Szutowicz E, Biernat W, Jankowski T, Och W, Staszkiewicz R, Chudzik M, Rogowski W, Flores N, Woditschka S, Li L, Goswami C, Thorat MA, Gokmen-Polar Y, Sledge GW, Steeg PS, Palmieri D, Badve SS: RAD51 and brain metastases (BM) in patients (pts) with HER2+ breast cancer [abstract]. ASCO Meeting Abstracts. J Clin Oncol, 2011 2011, 29:a634.

38. Dignam JJ, Dukic VM, Anderson SJ, Mamounas EP, Jeong JH, Costantino JP: Time-dependent patterns of recurrence after early stage breast cancer: preliminary observations and methodological issues [abstract]. ASCO Meeting Abstracts. J Clin Oncol 2007, 25:a536.
39. Burstein HJ, Harris LN, Gelman R, Lester SC, Nunes RA, Kaelin CM, Parker LM, Ellisen LW, Kuter I, Gadd MA, Christian RL, Kennedy PR, Borges VF, Bunnell CA, Younger J, Smith BL, Winer EP: Preoperative therapy with trastuzumab and paclitaxel followed by sequential adjuvant doxorubicin/cyclophosphamide for HER2 overexpressing stage II or III breast cancer: a pilot study. J Clin Oncol 2003, 21:46-53.

40. Buzdar AU, Ibrahim NK, Francis D, Booser DJ, Thomas ES, Theriault RL, Pusztai L, Green MC, Arun BK, Giordano SH, Cristofanilli M, Frye DK, Smith TL, Hunt KK, Singletary SE, Sahin AA, Ewer MS, Buchholz TA, Berry D, Hortobagyi GN: Significantly higher pathologic complete remission rate after neoadjuvant therapy with trastuzumab, paclitaxel, and epirubicin chemotherapy: results of a randomized trial in human epidermal growth factor receptor 2-positive operable breast cancer. J Clin Oncol 2005, 23:3676-3685.

41. Limentani SA, Brufsky AM, Erban JK, Jahanzeb M, Lewis D: Phase II study of neoadjuvant docetaxel, vinorelbine, and trastuzumab followed by surgery and adjuvant doxorubicin plus cyclophosphamide in women with human epidermal growth factor receptor 2-overexpressing locally advanced breast cancer. J Clin Oncol 2007, 25:1232-1238.

42. Buzdar AU, Valero V, Ibrahim NK, Francis D, Broglio KR, Theriault RL, Pusztai L, Green MC, Singletary SE, Hunt KK, Sahin AA, Esteva F, Symmans WF, Ewer MS, Buchholz TA, Hortobagyi GN: Neoadjuvant therapy with paclitaxel followed by 5 -fluorouracil, epirubicin, and cyclophosphamide chemotherapy and concurrent trastuzumab in human epidermal growth factor receptor 2-positive operable breast cancer: an update of the initial randomized study population and data of additional patients treated with the same regimen. Clin Cancer Res 2007, 13:228-233.

43. Hurley J, Doliny P, Reis I, Silva O, Gomez-Fernandez C, Velez P, Pauletti G, Powell JE, Pegram MD, Slamon DJ: Docetaxel, cisplatin, and trastuzumab as primary systemic therapy for human epidermal growth factor receptor 2-positive locally advanced breast cancer. J Clin Oncol 2006, 24:1831-1838.

44. Eiermann W, Baselga J, Semiglazov V, Byakhov M, Ciruelos E, Ojeda B, Feyereislova A, Zambetti M, Valagussa P, Gianni L: Hormone-receptor status and likelihood of predicting pathological complete response in the NOAH trial of neoadjuvant trastuzumab in patients with HER2positive locally advanced breast cancer [abstract]. Eur J Cancer 2008, 67: a228.

45. Untch M, Rezai M, Loibl S, Fasching PA, Huober J, Tesch H, Bauerfeind I, Hilfrich J, Eidtmann H, Gerber B, Hanusch C, Kühn T, du Bois A, Blohmer JU, Thomssen C, Dan Costa S, Jackisch C, Kaufmann M, Mehta K, von Minckwitz G: Neoadjuvant treatment with trastuzumab in HER2-positive breast cancer: results from the GeparQuattro study. J Clin Oncol 2010, 28:2024-2031.

46. von Minckwitz G, Blohmer JU, Costa S, Denkert C, Eidtmann H, Eiermann W, Gerber B, Hanusch C, Hilfrich J, Huober J, Jackisch C, Kaufmann M, Kümmel S, Paepke S, Schneeweiss A, Untch M, Zahm DM, Mehta K, Loibl S: Neoadjuvant chemotherapy adapted by interim response improves overall survival of primary breast cancer patients - results of the GeparTrio Trial [abstract]. San Antonio Breast Cancer Symposium 2011, aS32.

47. Pusztai L, Viale G, Kelly CM, Hudis CA: Estrogen and HER-2 receptor discordance between primary breast cancer and metastasis. Oncologist 2010, 15:1164-1168.

48. van de Ven S, Smit VT, Dekker TJ, Nortier JW, Kroep JR: Discordances in ER, PR and HER2 receptors after neoadjuvant chemotherapy in breast cancer. Cancer Treat Rev 2011, 37:422-430.

49. Niikura N, Liu J, Hayashi N, Mittendorf EA, Gong Y, Palla SL, Tokuda Y, Gonzalez-Angulo AM, Hortobagyi GN, Ueno NT: Loss of human epidermal growth factor receptor 2 (HER2) expression in metastatic sites of HER2overexpressing primary breast tumors. J Clin Oncol 2012, 30:593-599.

50. Mittendorf EA, Wu Y, Scaltriti M, Meric-Bernstam F, Hunt KK, Dawood S, Esteva FJ, Buzdar AU, Chen H, Hortobagyi GN, Baselga J, GonzalezAngulo AM: Loss of HER2 amplification following trastuzumab-based neoadjuvant systemic therapy and survival outcomes. Clin Cancer Res 2009, 15:7381-7388.

51. Goldhirsch A, Wood WC, Coates AS, Gelber RD, Thurlimann B, Senn HJ: Strategies for subtypes-dealing with the diversity of breast cancer: highlights of the St. Gallen International Expert Consensus on the 
Primary Therapy of Early Breast Cancer 2011. Ann Oncol 2011,

22:1736-1747.

52. Prat A, Perou CM: Deconstructing the molecular portraits of breast cancer. Mol Oncol 2010, 5:5-23.

doi:10.1186/bcr3324

Cite this article as: Vaz-Luis et al:: Impact of hormone receptor status on patterns of recurrence and clinical outcomes among patients with

human epidermal growth factor-2-positive breast cancer in the National

Comprehensive Cancer Network: a prospective cohort study. Breast

Cancer Research 2012 14:R129.

Submit your next manuscript to BioMed Central and take full advantage of:

- Convenient online submission

- Thorough peer review

- No space constraints or color figure charges

- Immediate publication on acceptance

- Inclusion in PubMed, CAS, Scopus and Google Scholar

- Research which is freely available for redistribution

Submit your manuscript at www.biomedcentral.com/submit 